\title{
Impact of Swelling Indices of Sokoto Clays on the Moulding Properties of the Clays in Sand Mixtures
}

\author{
Ihom A. Paul ${ }^{1}$, Suleiman U. Mohammed ${ }^{1}$, Nyior G. Bem ${ }^{2}$ \\ ${ }^{1}$ Department of Metallurgy, National Metallurgical Development Centre, Jos, Plateau State, Nigeria \\ ${ }^{2}$ Department of Metallurgical and Materials Engineering, Ahmadu Bello University, Zaria, Kaduna State, Nigeria \\ Email: draondonaphilip@gmail.com
}

Received June 28, 2012; revised July 30, 2012; accepted August 10, 2012

\begin{abstract}
The Impact of Swelling Indices of Sokoto Clays on the Moulding Properties of the Clays in Sand Mixtures was investigated. Four clays (labeled A, B, C, D) from different locations in Sokoto state of Nigeria were sampled. The sampling method was that for each deposit five samples were taken at different positions and then mixed together. At the laboratory they were washed to remove organic matter and then dried at $110^{\circ} \mathrm{C}$ in the oven. A laboratory ball mill was used to grind the dried clays. Each of the clay was then sampled for the determination of its swelling index. The determination of the moulding properties of the clays then followed. Only green compression strength, dry compression strength and green permeability, moulding properties were determined. The analysis of the result revealed that clay $\mathrm{B}$ has the highest green and dry strength values it had the highest green compression strength of $71.7 \mathrm{KN} / \mathrm{m}^{2}$ and the highest dry compression strength of $3225.75 \mathrm{KN} / \mathrm{m}^{2}$. Clay B also has the highest swelling index of $60 \%$ and very high degree of expansiveness when compared to the other three clays. Clay B was followed by clay A with swelling index of $25 \%$; the clay has high green and dry compression strength and a moderate degree of expansiveness. The inability of clay D with swelling index of $40 \%$ to be the next clay to clay B which has the highest swelling index of $60 \%$ among the four clays in terms of good moulding properties is an indication that high swelling index does not always mean good moulding properties in clay binders.
\end{abstract}

Keywords: Effect of Swelling Index; Clay; Sokoto; Properties; Mould Mixtures

\section{Introduction}

Clays have several properties; both chemical and physiccal properties. These properties are responsible for the various areas of application of clays. Clays are used as ceramic and refractory materials, used in the formulation of drilling fluids, as binders in foundry moulds, as binders for iron ore pellets in metallurgy, as catalyst in petroleum refining and production of petrochemicals, soil remediation, bleaching of oils, clarification of wines etc $[1,2]$.

Swelling index is one of the properties of clay it has generated a lot of investigation in the science and engineering world because of its vital links to areas of application of clay. In a work carried out by Paul, et al. [1] and RMRDC [2], the authors said that clays swell in water, creating a thixotropic gel (particularly bentonite) as a consequence of interlayer water adsorption. The numerous flakes and their extreme fineness contribute to the many of the industrial uses of clays while their separation by water molecules cause the well known expansion in volume of the mass called swelling index which creates the famous bellying viscosity properties which are essen- tial in oil drilling applications. The large surface areas of the particle promote adhesion and bond strength when mixed with inert materials like sand. The authors were able to show that swelling index affects green compression strength, dry compression strength, flowability and other properties, but could not show any correlation between swelling index and strength properties of clay bonded mould. Swelling index is linked to the exchangeable cat ions in clays these cations are sodium, calcium, magnesium, hydrogen and potassium, and the amount and types of these exchangeable cations influence the surface chemistry of the clay while the charge determines how the bentonite particles interact while in aqueous suspension. This interaction is very important in the development of bond strength of clays in moulding mixtures [3]. Also the large surface area of clay particles populated with these exchangeable ions give intense response to electrolytes in the surrounding water. Paul, et al. [2], and Paul, et al. [4] said in their works that there are other properties of clays in slurry form which are tested to give a measure of effectiveness in sand mixtures for mould making these include flowability, green and 
dry strengths, mouldability index, shatter index, compactability, bulk density, permeability and others. The authors in their various works investigated swelling index and tried to link it to moulding properties of sand mixtures. No clear relationship was however established.

Mittal and Shukla [5] analysed how critical this property of clay called swelling index is and outlined in details how it can be measured. A lot of interest has been generated on local raw materials sourcing for foundry shops and in particular clay. This informed the reason for this study. The objective of this work is to investigate the impact of swelling index of four clays on the moulding properties of the clays in sand mixtures.

\section{Materials and Methods}

\subsection{Materials}

Materials used for the research included, four (4) differrent clay samples which were collected from Sokoto state of Nigeria, kerosene oil from the filling station in Jos-Nigeria, distilled water from the analytical laboratory of NMDC Jos, and foundry sand from the foundry research shop of NMDC Jos.

\subsection{Equipment}

The equipment used were, sieve-425-micron IS sieve, oven, balance accurate to $0.01 \mathrm{~g}$ weighing, graduated glass cylinders, each $100 \mathrm{ml}$ capacity, sand rammer, electric permmeter, universal strength testing machine, laboratory ball mill, washing basins, filtering cloth, and mixer.

\subsection{Methods}

\subsubsection{Swelling Index}

The four clays sampled from Sokoto state using standard sampling techniques were washed and dried in the oven at $110^{\circ} \mathrm{C}$. The dried clays were then pulverized using laboratory ball mill and was ready for use without any treatment. $50 \mathrm{~g}$ of each of the clay sample was dried in the oven at $100^{\circ} \mathrm{C}-110^{\circ} \mathrm{C}$, it was then sieved through 425-micron-IS sieve. Two specimens of each clay weighing $10 \mathrm{~g}$ were taken. Two cylinders were taken one filled with kerosene and the other was filled with distilled water up to $90 \mathrm{ml}$ capacity. The samples were then poured gently, one portion into the kerosene the other portion into the distilled water. This was done for the four clays. The entrapped air was removed by gently shaking and stirring with a clean glass rod. The clays were allowed to stand for 24 hrs. The final (constant) volume of the clay specimen (not that of the liquid) in both the cylinders was read. Kerosene is a non-polar liquid causing no swelling of the clay. The level of the clay specimen in the graduated cylinder containing kerosene oil, was read as original volume of the clay sample. The level of the clay specimen in the second cylinder containing distilled water was taken as the free swelling level. Precautions taken during the experiment included, pouring the clay specimen in both the graduated glass cylinder gently, so that no clay particle remains stuck to the wall of the cylinder, sufficient time was given to the clay specimens to attain final equilibrium position of volume without any further change in the clay volumes. This took more than 24 hours, and the cylinders used were spacious enough to accommodate the volume increase.

\subsubsection{Moulding Properties Testing}

Moulding mixture made up of $8 \%$ of each clay in turn and water was prepared using a sand mixer made by Ridsdale and Dietert Company limited England. The water was varied from $2 \%$ to $6 \%$. The time for mixing every moulding mixture was kept constant at 15 minutes with the cover of the mixer closed to avoid moisture loss. After every batch the discharge slot was removed and the moulding mixture was discharged into a plastic container and immediately transferred to the weighing balance where the specimen was weighed and poured into the specimen tube using the pouring hopper. It was then taken to the sand rammer where it was rammed three times for the preparation of the standard test specimen 2 inches $\times 2$ inches $(50 \mathrm{~mm} \times 50 \mathrm{~mm})$. Specimens for permeability were transferred to the electric permmeter without removing them from the specimen tube for testing, while those for green compression strength were removed and tested using the universal strength testing machine made by Ridsdale and company limited. The specimens for dry compression strength were removed and dried in the oven at $105^{\circ} \mathrm{C}$ and allowed to cool before testing them using the universal strength testing machine. To ensure accuracy a minimum of two specimens were used for each test conducted and the average was used.

\section{Results and Discussion}

\subsection{Results}

The results of the work are as shown in Table $\mathbf{1}$ and Figures 1-4.

\subsection{Discussion}

Table 1 is the swelling indices of the four clays labeled A, $\mathrm{B}, \mathrm{C}$, and D with swelling index of $25 \%, 60 \%, 10 \%$, and $40 \%$ in that order. The same Table 1 shows that clay A have a degree of expansiveness that is moderate, the degree of expansiveness of clay B is very high, that of clay $\mathrm{C}$ is very low, and that of clay $\mathrm{D}$ is high. The table has clearly shown that swelling index is reflected in the degree of expansiveness the higher the swelling index, the higher the degree of expansiveness. This observation has been made by several researchers in the past, the re- 
Table 1. Investigated swelling indices of sokoto clays.

\begin{tabular}{ccccc}
\hline Sample identity & A & B & C & D \\
\hline $\begin{array}{c}\text { Swelling index } \\
\begin{array}{c}\text { Degree of } \\
\text { expansiveness }\end{array}\end{array}$ & Moderate & Very high & Low & High \\
\hline
\end{tabular}

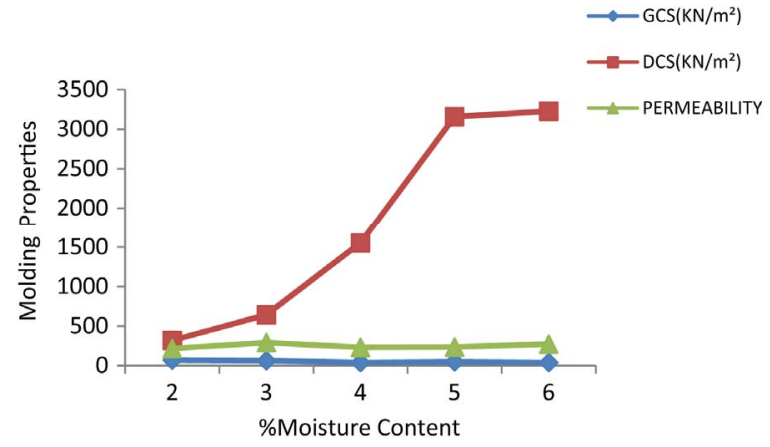

Figure 1. Moulding properties of clay A with swelling index of $25 \%$.

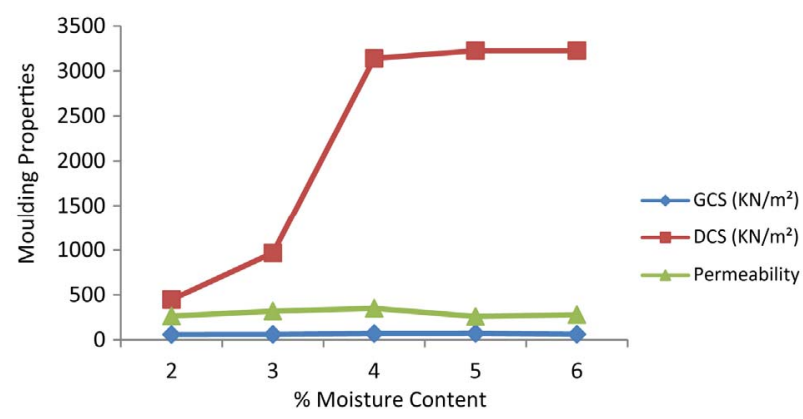

Figure 2. Moulding properties of clay $B$ with swelling index of $60 \%$.

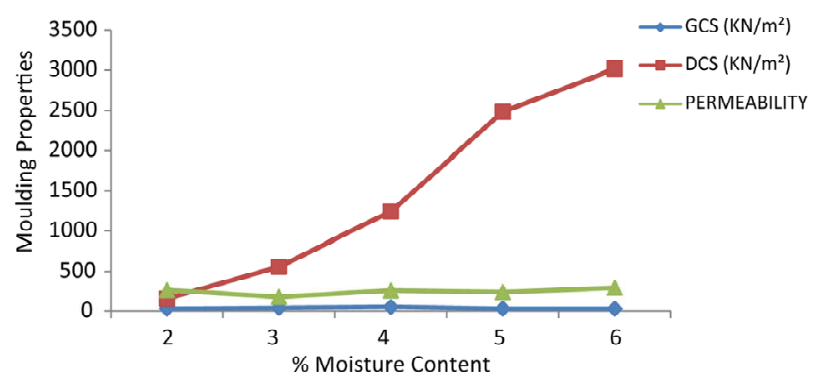

Figure 3. Moulding properties of clay $\mathrm{C}$ with swelling index of $10 \%$.

searchers in their different work have also said that swelling index is reflected in the degree of expansiveness of the clay [4-6].

Now it has been established that there is a positive correlation between swelling index and degree of expansiveness. The question then is what effect does swelling index have on the moulding properties of these clays? If the effect is positive it then means that the selection of clays for foundry use as binder for mould making can be

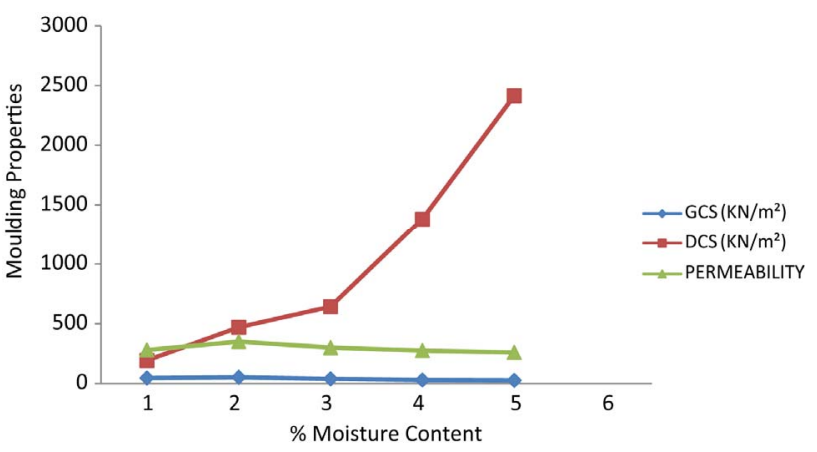

Figure 4. Moulding properties of clay $D$ with swelling index of $40 \%$.

based on the swelling index and by extension the degree of expansiveness since the two are related. Let's now examine Figures 1-4 to see the impact of swelling index on the moulding properties of the Sokoto clays.

Figure 1 shows the moulding properties of Sokoto clay A with swelling index of $25 \%$ the moulding properties plotted are, green compression strength, dry compression strength, and green permeability. According to Beeley [7] the dry strength properties of the clays will be a reflection of the nature of the clay (sodium-based bentonite, calcium-based bentonite, mixed bentonite, kaolinitic clay etc.). Sodium bentonite clays tend to have higher dry strengths than calcium bentonites and the other type of clays. The green compression strength curve of Figure 1 of clay A with swelling index of 25\% is lower than that of Figure $\mathbf{2}$ for clay B with swelling index of $60 \%$, it is higher than the curve of green compression strength of Figure $\mathbf{3}$ for clay $\mathrm{C}$ with swelling index of $10 \%$, and it is still higher than that of the green compression strength of Figure 4 for clay D with swelling index of $40 \%$. Comparing the green compression strength of the four clays it can be seen that between moisture content of $2 \%$ to $3 \%$ clay A has higher values of green compression strength i.e. $69 \mathrm{KN} / \mathrm{m}^{2}$ and 62.1 $\mathrm{kN} / \mathrm{m}^{2}$ as the moisture content is increased to $6 \%$ the values for the green compression strength of clay $\mathrm{B}$ remained higher than the other three clays throughout. Relating the values of swelling indices of the clays and the green compression values it can be said that clay B has higher moisture absorption capacity than the other clays. At $4 \%$ moisture it had a green compression strength of $70.3 \mathrm{kN} / \mathrm{m}^{2}$, at $5 \%$ moisture content it has a green compression strength of $71.7 \mathrm{kN} / \mathrm{m}^{2}$ and at $6 \%$ moisture content it has green compression strength of $62.1 \mathrm{kN} / \mathrm{m}^{2}$, the green compression strength dropped at 6\% moisture an indication that the clay was gradually exceeding its water absorption limit $[3,7,8]$.

Let's now look at dry compression strength of Figure 1 and relate it to the other Figures, the dry compression strength curve of Figure 1 is higher than that of Figures $\mathbf{3}$ and $\mathbf{4}$. Figures 2 which is the plot of moulding proper- 
ties of clay A shows that the curve of dry compression strength is higher than the other clays in Figures 1, 3 and 4; Figure 4 is the least. Clay $B$ with a swelling index of $60 \%$ and very high degree of expansiveness has consistently maintained high strength values both in the green and dry states. Clay B is followed by clay A which has a swelling index of $25 \%$ and a moderate degree of expansiveness. As mentioned above clay D which has a swelling index of $40 \%$ and a high degree of expansiveness has the least in terms of dry compression strength. As mentioned earlier the four clays are different and therefore do not show any relationship between swelling index and dry compression strength. The nature and type of clay determines its properties, it's obvious that clay B is sodium bentonite. The clay was plastic, has very high degree of expansiveness, high swelling index and high water absorption capacity which is typical of sodium bentonite clays $[6,9,10]$.

The permeability curve of Figure $\mathbf{1}$ is more or less the same with that of Figures 2 and 3 that of Figure $\mathbf{4}$ is slightly higher than that of Figure 1. All the four clays have high permeability which is even ideal for steel casting. For nonferrous casting permeability values in the range of 0 - 80 are ideal, however, for steel casting higher permeability values are required for gas escape (100 and above) [9,10].

The analysis of the results have not shown any clear relationship between the swelling indices of the clays and the green compression strength of the clays, no relationship is also seen between the swelling index and the dry compression strength of the clays. Beeley [7] in his work on clays said maximum swelling power is obtained in the sodium or sodium treated bentonites: these are notable for the high level of dry strength which they confer, whilst the calcium bentonites give maximum green strength. The scope of this work does not include the identification of the type of clay, because of that it is difficult to say that the clays with high swelling indices are sodium bentonites, but clay B is likely to be a sodium bentonite while clay A may be calcium bentonite. Clays $\mathrm{C}$ and $\mathrm{D}$ may be kaolin or low grade calcium bentonite or even illite clay. Despite the high swelling index exhibit by clay $\mathrm{D}$ it did not have the high plasticity exhibited by clay B this was observed during the experiment. Clays B and A with swelling indices of $60 \%$ and $25 \%$, have the highest strength values, the strength values were higher than the other clays both in the green and dry conditions. With this study we agree with several authors [11-13] who say that the strength of clays in moulding mixtures depend on the nature of the clay, the exchangeable ions present and the moisture content these parameters determine the strength of the bond formed between the clay particles, the sand grains and the water molecules. The swelling index might be an indication of good binding clay, but indicates more the capacity of clay to absorb moisture [14]. Rundman [15] have used two models to explain the strength property of clays in moulding mixture and none of these models relate to the swelling index, the two models are a low moisture model involving polarized water molecules on both clay and sand and a high moisture model involving ionic bonds between the sodium ions and the water molecules. The polar bonding at low moisture is referred to as rigid water bonding and the ionic water bonding at high moisture is referred to as bridge bonding. The polar bonds are thought to be quite weak and are very temperature dependent, while the ionic bonds are relatively strong and therefore less temperature dependent. Confirmation of the model comes when the adsorbed ionic species are removed from the clay by an ion exchange process; the result is the room temperature properties at high moisture dropping rapidly to zero. The ionic model is what was observed in clay B when the moisture content was above 3\% the compression strength values increased indicating stronger bridge bonding.

We can therefore draw these inferences that the clays do not show any clear relationship between the swelling index and the moulding properties, and that the clays are not the same to give a consistent result for analysis. Different clays have different moulding properties in green and dry state [16]. Among the four clays clay B has the highest green compression strength of $71.7 \mathrm{KN} / \mathrm{m}^{2}$ and highest dry compression strength of $3225.75 \mathrm{KN} / \mathrm{m}^{2}$.

\section{Conclusions}

The study has shown that the clays are not the same type and therefore a generalized relationship between the swelling index and the moulding properties can not be established. Based on this premise the following conclusions have been drawn:

1) The study has not shown any relationship between swelling index and the moulding properties determined

2) The study have shown that the strength properties depend more on the bonding properties of the clays and not the swelling index

3) Clay B with the highest swelling index (60\%) has the highest green compression strength and dry compression strength properties.

4) The clays (A and C) with moderate and low degree of expansiveness have higher green and dry strength properties than the clay D with high degree of expansiveness.

5) The moulding properties of clay B is typical of sodium bentonite clay

6) The moulding properties of clays A, C and D is typical of calcium bentonite and kaolin clays

7) Clays with high swelling index also have high degree of expansion. 


\section{Acknowledgement}

The authors sincerely acknowledge the Centre for allowing them to use the facilities in their foundryshop for this work.

\section{REFERENCES}

[1] Raw Materials Research and Development Council (RMRDC), “Technical Brief on Minerals in Nigeria, Bentonite,” Raw Materials Research and Development Council, Abuja, 1999, pp. 5-10.

[2] I. A. Paul, S. A. Yaro and V. S. Aigbodion, "Beneficiation of Bende Ameki Bentonite Clay," Ife Journal of Technology, Vol. 15, No. 2, 2006, pp. 93-98.

[3] A. J. Clegg, "Precision Casting Processes," Pergamon Press, Oxford, 1991.

[4] I. A. Paul and O. O. Olubajo, "Investigation of Bende Ameki Clay's Foundry Properties and its Suitability as a Binder For Sand Casting," NMS Proceedings of the 21st Annual conference Enugu-2002, Enugu, 26-30 October 2002, pp. 20-30.

[5] S. Mittal and J. P. Shukla, "Soil Testing for Engineers," 5th Edition, Khanna Publishers Nai Sarak, Delhi, 2008.

[6] I. A. Paul, "Foundry Raw Materials for sand casting and testing Procedures,” $\mathrm{A}^{2} \mathrm{P}^{2}$ Transcendent Engineering, Jos, 2012.

[7] P. R. Beeley, "Foundry Technology," 4th Edition, Butterworth Scientific, London, 1982.
[8] R. W. Heine, C. R. Loper Jr. and P. C. Rosenthal, "Principles of Metal Casting,” 2nd Edition, Tata Mcgraw Hill Publishing Company Limited, New Delhi, 1967.

[9] J. R. Brown, “Foseco Foundryman's Handbook,” 10th Edition, Butterworth Heinemann Ltd., Linacre House, Jordan Hill Oxford, 1994.

[10] NMDC, "Databank of Raw Materials for the Metallurgical Industry,” National Etallurgical Development Centre, Jos, 2008, p. 69.

[11] I. A. Paul, A. Johnson, A. Bam and E. E. Anbua, "Investigation of the Properties of a Nigerian and a Liberian Bentonite for Foundry Application,” Continental Journal of Engineering Sciences, Vol. 4, No. 2, 2009, pp. 6-11.

[12] R. K. Jain, "Production Technology,” Khanna Publishers, Delhi, 2009.

[13] I. A. Paul, S. A. Yaro and V. S. Aigbodion, "Application of Multiple Regression Model to the Study of Foundry Clay bonded Sand Mixtures,” Journal of Information and Communication and Computing Technologies, Vol. 2 No. 1, 2006, pp. 160-168.

[14] J. A. Omotoyinbo and O. O. Oluwole, "Working Properties of Some Selected Refractory Clay Deposits in South Western Nigeria,” Jessie Mae Monroe Elementary School, Vol. 7, No. 3, 2008, pp. 233-245.

[15] K. B. Rundman, “Metal Casting,” Department of Material Science and Engineering Michigan Technology University, Michagan, 2000, pp. 17-19.

[16] C. O. Nwajagu, "Foundry Theory and Practice," ABC Publishers, Enugu, 1994. 